Final version:

Lindgreen, A., Vallaster, C., and Vanhamme, J. (2001), "Reflections on the $\mathrm{PhD}$ process: the experiences of three survivors", The Marketing Review, Vol. 1, No. 4, pp. 505-529. (ISSN 1469$347 \mathrm{X})$

For full article, please contact LindgreenA@ cardiff.ac.uk

\title{
Reflections on the PhD Process: The Experiences of Three Survivors
}

\author{
Adam Lindgreen, Catholic University of Louvain ${ }^{1,2,3}$ \\ Christine Vallaster, Leopold-Franzens University of Innsbruck \\ Joëlle Vanhamme, Catholic University of Louvain
}

\footnotetext{
${ }^{1}$ The authors all contributed equally and have been listed alphabetically.

${ }^{2}$ Correspondence should be addressed to Adam Lindgreen, Department of Marketing, Institut d'Administration et Gestion, Catholic University of Louvain, 1 Place Des Doyens, 1348 Louvain-la-Neuve. Telephone + 32 - 10478481. Fax + 32 - 1047 8324. Email Lindgreen@mark.ucl.ac.be.

${ }^{3}$ The authors have benefited much from participating in the doctoral colloquiums of the European Marketing Academy $(1998,2000)$, the Australia and New Zealand Marketing Academy $(1998,1999)$ and the Academy of Marketing $(1999,2000)$. The authors have also learned much from the seminars of the doctoral education network of the European Institute for Advanced Studies in Management. They wish to thank the organisers of all of these events for many valuable suggestions. Last but not least, the authors would like to thank their academic supervisors for their support and encouragement over the last years.
} 


\begin{abstract}
In the literature it is possible for doctoral candidates to find a broad range of guidelines on how to write a successful doctoral thesis. For example, in 1999 the Australasian Marketing Journal published an article on a structured approach to presenting doctoral theses, with an in-depth examination of the sections that are expected to appear in a doctoral thesis (Perry 1999). More recently, the Marketing Review is currently printing a series of four articles on general guidelines on how to undertake a research project (Baker 2000a, 2000b). Candidates are often struggling with their theses one reason being that they find it difficult to present their research findings, and the efforts made by Perry and Baker are thus to be applauded; and the articles should serve both to motivate and guide candidates. The present article, however, focuses on what the authors consider to be one key, fundamentally unresolved, issue surrounding the Perry and Baker articles: the process of actually getting to the point of presenting the research findings in a doctoral thesis. The authors first share with the reader their personal experiences of going through a typical doctoral programme before offering their best pieces of advice. Overall, the list of dos and don'ts can help candidates to get on top of their doctoral research instead of the doctoral research getting on top of the candidates.
\end{abstract}

\title{
Introduction
}

Numerous books on how to write a successful doctoral thesis have appeared in the past (e.g., Drummond 1995; Lewins 1993; Mace 1997; Madsen 1983; Mauch 1998; Tremewan 1997; Turabian 1996). Similar publications have been contributed to academic journals. For example, in 1999 the Australasian Marketing Journal published an article by Perry dealing with a structured approach to presenting doctoral theses (Perry 1999). First, the article considers criteria for judging a doctoral thesis; justification for the structure of a doctoral thesis; and matters of style, such as spelling style, writing style and reference style. Second, the article offers an in-depth examination of the sections that are expected to appear in a doctoral thesis. That is, introduction, literature 
review, methodology, analysis of data, conclusions and implications. The article by Perry describes a structured approach for presenting a doctoral thesis, and his appears to be a more comprehensive approach than earlier ones (e.g., Clark 1986; Pratt 1984; Witcher 1990).

More recently, the Marketing Review is currently printing a series of four articles on general guidelines on how to undertake a research project (Baker 2000a, 2000b). The first article dealt with practical advice on the identification and selection of a suitable topic while the second one examined the purposes and scope of a literature review. The many lists of pieces of advice to the doctoral candidates have contributed to the strength of these articles.

Doctoral candidates are often struggling with their theses one reason being that they find it difficult to present their research findings, and the efforts by Perry and Baker are thus to be applauded; and the articles should serve both to motivate and guide candidates. The present article focuses on what the authors consider to be one key, fundamentally unresolved, issue surrounding the Perry and Baker articles. That is, candidates may be left with an impression that all what is needed to be awarded the "Dr" accolade is much perspiration - and a little inspiration. The real story is, however, nothing like that. In this article, the authors describe the emerging process from the initial point of actually thinking about carrying out a doctoral research to the

point of synthesising the research findings into a doctoral thesis. Throughout the article, the authors share their personal experiences with the reader before offering their best pieces of advice. Finally, the list of Dos and Don'ts at the end of the article can help candidates to get on top of their doctoral research instead of the doctoral research getting on top of the candidates.

\section{Research Objectives}

The article deals with the following two issues:

- Exploring emergent themes from carrying out a doctoral research programme - based upon the experiences of the authors; and 
- Offering the authors' best pieces of advice on how to manage the process from the initial point of actually thinking about carrying out a doctoral research to the point of synthesising the research findings into a doctoral thesis.

Three-stage Doctoral Research Process

In order to present their experiences, the authors found it useful to divide the doctoral research process into three distinct phases:

- Phase one: getting started;

- Phase two: surviving the ups and downs; and

- Phase three: reaching closure.

For each of the stages the authors will first share with the reader their experiences before moving on to offering their best pieces of advice.

\section{Phase One: Getting Started}

Personal Experience: Adam Lindgreen

There were several reasons for why I wanted to undertake a doctoral research programme. For one thing, the successful completion of such a programme is an official blueprint that says, 'This person is capable of carrying out research using well-established scientific methodologies', which is very satisfactory in its own right. On top of that, most universities require you to have this blueprint if you want to pursue a career within academia - and this was what I had always wished for.

The decision of embarking on a programme involves not only you but also your partner, family and friends. For example, to a large extent the research will decide when you have time off for socialising; it may also determine that you must go to another country to carry out parts of your 
field studies. I thus left Denmark and spent 18 months in England and 18 months in New Zealand - and in between I attended conferences in other countries. Fortunately, I received the full support of my parents and friends. Most importantly, I had the unconditional understanding of my girlfriend who herself is a doctoral candidate. For my own part, I had earlier lived and worked in other countries than Denmark and the idea of being able to live in yet another country for an extended period appealed very much to me.

In Denmark, universities or research academies employ the candidates throughout their research, which can take place at an institution in Denmark or at an institution abroad. The requirements and the employment packages are much similar. I applied for one of 33 scholarships with the Danish Research Academy. This institution funds some 100 students at any given time. My monthly salary was US\$ 1,625 after all taxes had been paid. In addition, I received - tax-free US\$ 1,000 for my relocation and a monthly US\$250 toward a pension scheme. Realizing that there are significant costs associated with most research, the Danish Research Academy also set aside US\$ 10,750 every year that would cover fees for tuition, seminars and conferences. Expenses for special equipment (e.g., the NUDIST software programme), travelling, health insurance and publication of the final doctoral thesis were also covered. Although the employment was very generous, I still had to find other funds for my research expenses. Throughout the last 200 years, wealthy Danish people have set up private grants that support researchers and from such funds I received a total of US\$ 6,250 (tax free). I would also lecture, which provided me with US\$ 8,000 over the three years. Finally, Cranfield University and the University of Auckland supported me with US\$ 3,150 so that I could participate in international marketing conferences.

At the Danish Research Academy, both the applicant's academic background and the anticipated contributions of the research, which is described by the candidate, guide the selection process. I made a point of identifying a project where I could combine my MSc in Food Science and Technology with my MBA. The research, 'The emergence and rise of relationship marketing: an empirical investigation that seeks to describe and explore particular aspects of relationship marketing in the international food and wine industries', would have potential interest for the 
Danish food industry. With this approach, I believed that the Danish Research Academy would view my application favourably.

It was a requirement that $\mathrm{I}$ be accepted into a doctoral programme at a foreign university that is among the best ones in the world. For the purpose of my research, it was convenient to stay in England and New Zealand: both Denmark and New Zealand are thus among the major food and wine producers for the British consumer. I decided for Cranfield University, one of Europe's leading management schools and internationally recognized as a center within relationship marketing. The university also has strong research in food marketing. For the last 18 months of my programme, I chose to be with the University of Auckland, a member of Universitas 21, which is an association of major, research-intensive international universities. And, the university has strong research in relationship marketing.

After having identified Cranfield University as the would-be university, I simply wrote to its Department of Marketing to express my interest in embarking on a doctoral programme. In December 1995, I was invited to visit the department and to discuss possible research projects so that I could finish my application for the Danish Research Academy. I sent in the application in January 1996 and was accepted with the academy in April 1996. At a later stage, I used the same approach with the University of Auckland except that I in this case met with the Head of Department at an international conference.

Isaac Newton once wrote, "If I have seen further, it is by standing on the shoulders of giants", and so you will need all the help that you can get. Your supervisor will be the most important person guiding you through the research. Any relationship should be beneficial to both parties. For example, the supervisors hope to do research with the candidate because they themselves often have only limited time for such activities. The supervisors want a candidate to be curious, independent, energetic, determined and creative. The candidates wish the supervisor to be understanding and knowledgeable, as you want to have both enjoyable thoughtful chats and more goal/driven meetings. Joint publications are often the outcome of a successful relationship. 
The actual identification of my research questions happened over a six-month period. Indeed, the adding of sub-questions took place over a two-year period. This is a common procedure within grounded theory-based research, which I applied in my research. I found it particular useful to discuss my thoughts with my supervisor and thesis committee, but also with other colleagues and candidates that at I met at special doctoral colloquiums or conferences.

\section{Personal Experience: Christine Vallaster}

If people had asked me some four years ago whether I would ever embark on a doctoral programme on business, the answer probably would have been something like, "Do I look as if I want to waste precious time with theoretical work?" Only after a friend who was then working at the Marketing Group had carefully introduced me to the world of academia by assigning me to a research project did I begin to show interest in doing research. With hindsight, I think he was one of the most influential people who shaped my decision to enter a doctoral programme.

However, there were many other factors that contributed along the decision-making process. For example, a very pragmatic issue at that time was the consideration that I could prolong my student life for a few more years. Hence, the years needed for finishing my doctoral research programme would give me some more 'air to breath and think about' what I really wanted to do with my life. Moreover, doctoral research candidates I knew at that time reported experiences, which seemed to be very challenging. The individual and subject-related learning issue fascinated and appealed to me - but I would only discover many months later what this actually meant for me. Finally, apart from career and professional considerations, a relatively easy access to doctoral programmes (i.e., no student intake limitations and no study fees) in Austria at that time enhanced my decision making process.

The decision to select Leopold-Franzens University of Innsbruck as the main research institution was rather clear from the beginning, although I was tempted in choosing an organisation with a better reputation worldwide. However, the aspect of working in a familiar environment with a firm social network and transparent university structure comforted me more than moving into an 
unknown environment. The decision to choose the Marketing Group and my future supervisor was guided by high standards, though. If I were to spend four to five years of my life I would aim to produce a high-profile thesis, which was supported by an internationally recognised supervisor well established in the academic community.

The success of the doctoral thesis rises and falls with the relationship to your supervisor(s): From the start, an independent working style with a lot of room for creativity and curiosity characterised my co-operation with my main supervisor. This approach to supervision provoked and allowed a thinking process partly crossing mainstream borders in the area of marketing. If I needed more guidance I could request it: frequently held discussions, relatively quick responses to written parts of the thesis, and emotional support provided more direction.

The process of searching an external supervisor came later in the process of writing and was primarily guided by the criteria of knowledge in the subject of the doctoral research. This approach allowed an exchange of different perspectives and the establishment of fruitful contacts. The process of getting focused on my research issue was exciting, overwhelming and - to some extent - also frustrating, as I began to stray not only into many fields of marketing but also in the areas of psychology, sociology and ethnography. I was determined to integrate my personal hobbyhorse of culture and ethnicity. In fact, I encountered some difficulties in getting focused on my research problem. The attendance of doctoral conferences (the European Marketing Academy's Doctorial Colloquium) and a continuous exchange of experiences with other doctoral students and academics helped me to streamline my thoughts. Furthermore, a four-month involvement with the Marketing Group as a research assistant gave me some more insight into the academic world and supported the focusing process through discussions with department members. Finally, after some six months I finalised my problem statement.

However, I soon figured out that with my selected research topic and the methodology applied I entered a parquet that was somewhat outside of mainstream marketing. Heard criticism included that the research issue was considered too complex and too flabby to be considered as serious sciences. For me as a novice in academia these comments were rather discouraging, but backed- 
up by my supervisor I decided to stick with the research topic and to aim for something that I had always wanted to do, i.e. to carry out a research project in a different cultural setting. I chose Hong Kong in China.

\section{Personal Experience: Joëlle Vanhamme}

Having finished my master's degrees in Marketing and Management, I wanted to continue within academia - and going through a doctoral research programme was the entry ticket. When I initially embarked on the process that would eventually lead to a position at a university, I had no idea what my research topic would be about except that the topic should be in the field of consumer behavior, as I had always liked this area. First, I would need research funding, however. In Belgium, candidates are usually first hired as a teaching and research assistant, which allows them to spend 50 per cent of their time on the research. At a later stage, and after having developed a well-defined proposal, the candidates can apply for a grant from either the Belgian National Fund for Scientific Research or the Intercollegiate Centre for Management Sciences, which will allow them to focus 100 per cent on the research. Not many grants are available, however. Moreover, you need efficient time management, as applications must be handed in one year before you actually want to start working under such a scheme. After all taxes, the monthly salary is about US\$1,400. On top of that, you will have contributions toward your pension and social security. You will be entitled to use all the facilities and equipment that are available at the university where you will be doing your research. However, not all universities provide their candidates with a budget that allows them to carry out research, to attend seminars and conference or to do any travelling. There are a number of grants that candidates can apply for but these grants usually only cover parts of the expenses.

Unfortunately, there was no job available as a teaching and research assistant after I had completed my MA degrees in June 1996 so I started working in the private sector. At the same time, though, I continued to read books and articles on consumer behavior and paid much attention to the articles that suggested new avenues for research to be carried out. One of the articles, written by my future supervisor, mentioned that there had been no research on the 
emotion of surprise. I had always been interested in psychology and, therefore, thought that surprise would be an interesting research topic. Along with working in the private sector and reading up on possible research topics, I kept in touch with the academic world so that I could be the next one on the list for a job as a teaching and research assistant. The Catholic University of Louvain - which is the most renowned university in Belgium - hired me in September 1997.

I now started to find myself a supervisor and thought the best person would be the author of the article on the emotion of surprise. So when he lectured on a course on consumer behaviour, I signed up and went on to discussing the topic with him. But as he was from another university I also needed a supervisor from the university from where I eventually would get my doctorate degree. I opted for a supervisor who was 'complementary' to the first one. Although the system with two supervisors may have some disadvantages (e.g., they may not agree on which direction the research should take), it has worked out well for me.

During the first six months of 1998, I read a number of articles on surprise in the psychology literature. This was quite difficult, as I had no previous knowledge of psychology and I therefore decided to embark on an MA in Psychology. I had also to define in what context I would study the emotion of surprise. There were, basically, two areas: (1) the pre-purchase/pre-consumption area and, more specifically, the field of advertising and (2) the post-purchase area. I went for post-consumption and, more specifically, satisfaction because articles mentioned the lack of research in this area. Furthermore, the post-consumption literature is less developed than the preconsumption literature. Working on surprise was an advantage, but also a disadvantage since I could not rely on existing marketing research and build on that. However, with my literature review in both fields (surprise and satisfaction) I could build a first model of influence of surprise on satisfaction that would have to be defined more thoroughly through additional exploratory research. My research was then defined precise enough so that I could apply for a full doctoral grant with the Belgian National Fund for Scientific Research. I applied in December 1998 and was accepted in October 1999. 


\section{The Authors' Best Pieces of Advice}

Why do I want to undertake a doctoral programme? The wish for undertaking a doctoral research must be firm and motivating, as the research will demand at least three-four years of your life. The question of why you would want to engage in such a research is probably the most important question that you should ask yourself. No one but you will know the answer.

What are the consequences of doing a doctoral programme? You will experience the whole palette of emotions: joy and pride, but also guilt, frustration, anger and perhaps even depression. The programme lasts for a long time and will probably include a stay at a foreign university for at least six months. It is, therefore, important that your partner, family and friends support you. You must also be willing to accept other cultures and to improve your language skills. Perhaps you will have to work under a research paradigm that is different to what you are used to.

Does a doctoral programme require a specific type of personality/qualification? You should be curious and critical, as you will be expected to contribute to the scientific pool of knowledge. You must be independent, energetic, determined and creative. However, doing scientific work requires a high degree of patience - with yourself and your environment: the process of writing a doctoral research takes time. Nevertheless, you must have self-discipline, persistency and a skill for organizing your work. The love for reading is important: a colleague of ours recently told us that he estimated that he had read some 45,000 pages of literature as a part of his research. If you feel that you are lacking important knowledge in a specific area closely related to your doctoral research do not hesitate to attend courses or seminars.

Do I have the financial resources to do a doctoral programme? There are significant costs of doing a doctoral programme. In our cases the annual tuition fees were US\$ 5,050 (for Adam Lindgreen), none ${ }^{4}$ (for Christine Vallaster) and US\$ 200 (for Joëlle Vanhamme). There are expenses for seminars, conferences, travelling and perhaps insurance. You also have general living expenses. You may apply for a university or a governmental grant so be informed of any

\footnotetext{
${ }^{4}$ Beginning with autumn 2001, Austria will introduce student fees of around US\$ 360 per semester.
} 
deadlines. Some of the organizations that offer seminars thus have grants. Individuals can have set up grants for researchers. You could work part time for the university or a private organization, although this may prolong the necessary period for finishing your research.

Where do I want to do the doctoral programme? You should study the ranking of the programmes that you are considering. Are these universities known within your field of research? You ought to examine the networks that the university is a part of. You can talk with people who have finished a programme at the university. Finally, but not least: where is the university situated? You may want to live in a city that never sleeps, or you may prefer the university in a more rural setting. The choice is an important one because you will stay at the university for three-four years.

Who should be my supervisor? Both you and your supervisor should benefit from the relationship. You should meet with your supervisor on a regular basis, which would secure that you receive guidance but that you are also left with room to live out your own ideas. As you are only one of your supervisor's responsibilities, you must be patient and, at the same time, persistent when asking for feedback. You must also demonstrate independence and commitment, and you must show initiative. Your supervisor should be understanding and knowledgeable: when you feel blue he should consulate you. The reputation of the supervisor might also be an important factor, as this could facilitate your access to a scientific research network. Prepare an agenda when you want to meet with your supervisor, and do this in advance, and agree on the agenda and the outcomes of the meeting. Do appreciate that a supervisor may not know all the answers but can guide you in the right direction. You might also consider having two supervisors. You should bear in mind that the relationship between a candidate and a supervisor goes through many different stages: expert-novice, counsellor-client, guide-explorer, colleague-colleague and friend-friend.

How do I get focused on the research? In the beginning, you have only a vague idea of what you will want to research. The requirement for finishing a doctoral programme successfully is that you have added to the scientific pool of knowledge (e.g., insight into theory, research methodology or managerial implications). Consider adding several smaller bricks of new 
knowledge in an existing area instead of a single big brick of new knowledge in an area that has not yet been investigated - although both approaches are equally valid the former is often more doable and defendable. But if you opt for the latter approach and if you succeed, you will have created your own brand name. Knowledge can be in terms of theory or research methodology. This has been illustrated in Figure $1 .^{5}$

\section{Figure 1. Adding to the scientific pool of knowledge in terms of theory and research methodology.}

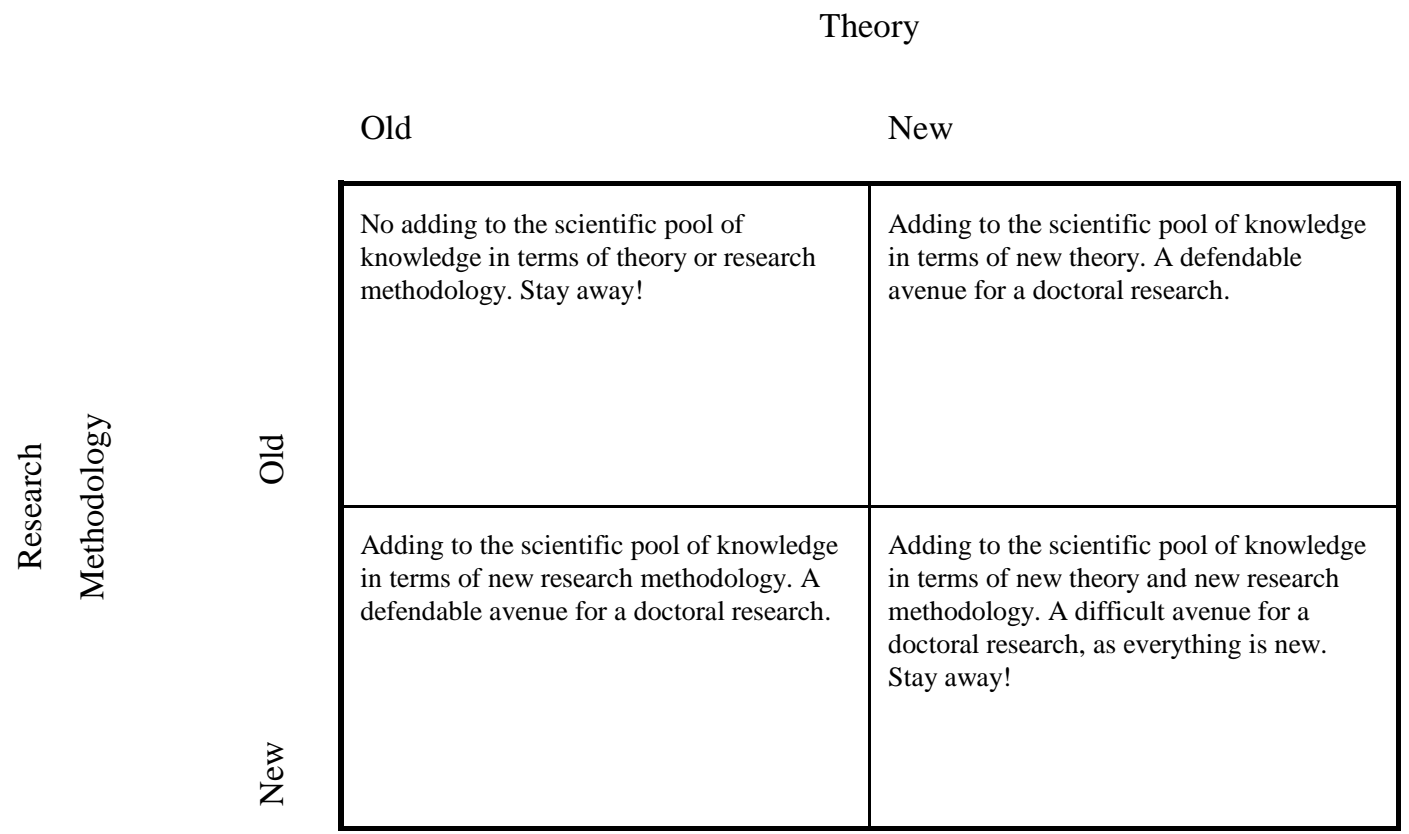

Read the relevant literature and consult with colleagues and researchers in order to get focused. It is further recommended to go to doctoral seminars where you will discuss with professors and other candidates. Perhaps you want to write as you go along. Make sure that your database and your reference system are set up properly. It has proved helpful to always have a little notebook so that you can write down your ideas. Write conference papers, as these will help you in the write-up of the thesis. And you should not be depressed if the process of getting focused takes six months or even longer. The 'law of 3Ts' dictates that things take time. Overall, the research

\footnotetext{
${ }^{5}$ The authors were introduced to this way of thinking of theory and research methodology at the Academy of Marketing's Doctoral Colloquium in 1999.
} 
question is paramount because not until you have written this question down will you actually know what are trying to achieve. Not before you have done this can you carry out empirical research.

\section{Table 1. Issues to be considered under the first phase}

\begin{tabular}{|c|c|}
\hline Issue & Examples \\
\hline $\begin{array}{l}\text { Why do I want to undertake a doctoral } \\
\text { programme? }\end{array}$ & - $\quad$ Firm and motivating aim for research \\
\hline $\begin{array}{l}\text { What are the consequences of doing a } \\
\text { doctoral programme? }\end{array}$ & $\begin{array}{ll}\text { - } & \text { Experiences of joy and pride } \\
\text { - } & \text { Experiences guilt, frustration, anger and perhaps depression } \\
\text { - } & \text { Support from partner, family and friends } \\
\text { - } & \text { Willingness to accept other cultures, to improve language skills } \\
& \text { and to work under a new research paradigm }\end{array}$ \\
\hline $\begin{array}{l}\text { Does a doctoral programme require a } \\
\text { specific type of personality/qualification? }\end{array}$ & $\begin{array}{ll}\text { - } & \text { Curious and critical mind } \\
\text { - } & \text { Independence, energy, determinism and creativity } \\
\text { - } & \text { Be Patient with yourself and your social environment } \\
\text { - } & \text { Self-discipline, persistency and organizing skill } \\
\text { - } & \text { Love for reading huge amounts of literature }\end{array}$ \\
\hline $\begin{array}{l}\text { Do I have the financial resources to do a } \\
\text { doctoral programme? }\end{array}$ & $\begin{array}{l}\text { - Tuition fee } \\
\text { - } \quad \text { Expenses for seminars, conferences, travelling and perhaps } \\
\text { insurance } \\
\text { - } \quad \text { General living expenses } \\
\text { - } \quad \text { University or governmental grant } \\
\text { Grants for private organizations or individuals (pay attention to } \\
\text { any deadlines) } \\
\text { Part-time work }\end{array}$ \\
\hline $\begin{array}{l}\text { Where do I want to do the doctoral } \\
\text { programme? }\end{array}$ & $\begin{array}{ll}\text { - } & \text { Ranking of university } \\
\text { - } & \text { Reputation of the university's research output } \\
\text { - } & \text { Location of university (city versus countryside) } \\
\text { - } & \text { Office facilities (computer, printer, photocopier, software, etc) }\end{array}$ \\
\hline Who should be my supervisor? & $\begin{array}{l}\text { - One or several supervisors? } \\
\text { - } \quad \text { Understanding and knowledgeable person } \\
\text { - Reputation of the supervisor(s) }\end{array}$ \\
\hline How do I get focused on the research? & $\begin{array}{l}\text { - Small bricks of new knowledge versus a single big brick of new } \\
\text { knowledge } \\
\text { - } \text { Help from colleagues, researchers and other candidates } \\
\text { - } \quad \text { Write-ups as you go along } \\
\text { - } \quad \text { Notebooks } \\
\text { - } \quad \text { Database and reference system }\end{array}$ \\
\hline
\end{tabular}




\section{Phase Two: Surviving the Ups and Downs}

Personal Experience: Adam Lindgreen

I found networking particularly useful. The actual process of networking could start with my supervisor who would introduce me to other colleagues and researchers. I would also be proactive myself: For example, I participated in conferences, which allowed me to receive valuable feedback from researchers within the same field of specialization. Later, I would write papers or articles with some of these researchers. One type of networking has been exceptionally beneficial: the doctoral network. I took part of the doctoral colloquiums of the European Marketing Academy and of the Academy of Marketing and here I met other candidates who were struggling with the same problems that I was facing. We kept contact with each other, also after we have finished our doctoral programme: after all, we are still facing similar challenges and can, therefore, help each other. I also participated in seminars specially designed for doctoral candidates - at one such seminar I met my partner and future wife.

To stay within academia one must publish. Even if you want to pursue another career it is still worthwhile to publish parts of your doctoral research because you will receive feedback that can prove valuable when you write up your dissertation. In November 1999, I had finished all my empirical research. Since I had published regularly the write-up of the thesis proved not to be the dreadful thing that everyone had talked about: I thus finished the chapter of research methodology in December 1999 while I completed all of the remaining chapters in the period February-May 2000. There is an additional benefit of writing papers and articles: You build on your curriculum vitae, which is extremely important when you apply for a position. In my particular case, the funniest paper was with my girlfriend. At the time of writing, I was living in New Zealand and she was in Europe, but with the paper accepted for the conference of the Australia-New Zealand Marketing Academy, she was able to come to Australia and, subsequently, New Zealand.

Although I have focused much on the need to work hard I still lived the "dolce vita" at times. This was almost like rewarding myself when I had done something extraordinary or, perhaps, just 
carried out the weekly "burden" for finishing my programme. I would watch some television most nights and I would go to the cinema with my girlfriend. At some times, I would take time off so that when I participated in a conference I went on a well-deserved holiday afterwards. In fact, I have never travelled as much as I did during my doctoral research, which took me to such exotic places as Argentina, Morocco, Thailand and the Easter Island.

I really experienced only two lows during my doctoral programme. The first low happened a month after I have arrived to Cranfield University: I thought that I would identify the research problem during the first month of my studies, that I would then carry out my interviews over the next four months and that I finally would write up my thesis in two-three months - and then go travelling for the remaining part of the three-year programme. Nothing happened like that, however, and my realisation of this caused the first low. The other low happened less than a month before I would send off my thesis: I had plan to attend a conference in the Netherlands just after having mailed the thesis and then to finish administrative tasks in New Zealand before having a holiday and attending two other conferences before the defence. I remember that my supervisor, who naturally was looking after my best interests, wrote me an email asking me how I could plan for these activities, as there was still a lot to do. I cried, my girlfriend cried, and life was not worth living. But I survived because I discussed with my supervisors in Britain and New Zealand, and I discussed with my girlfriend and other colleagues. I certainly experienced my part of the inevitable lows that form part of every doctoral programme.

\section{Personal Experience: Christine Vallaster}

The reason why I chose the Chinese culture as the field of research was because the West is still rather ignorant of the economical and social power that rests in this region. With its unique culture so different from that of the West, high demands and requirements are made on both, Chinese and Western managers. Hong Kong, the city at the end of the Pearl River, was considered an ideal setting where the cross-cultural contact between the Chinese and Western cultures had been taking place for over 100 years. 
The preparation phase started long before the research area was moved from small, quiet Innsbruck to energetic, dynamic Hong Kong. Reading literature on Chinese culture gave me confidence that I would correctly interpret Chinese behaviour. Weggel's statement (1994) that one has to experience Chinese culture in order to grasp only a glimpse of it did not begin to make sense until months later. Academic contributions on the topic of cross-cultural research helped me become aware of potential fallacies and dangers inherent in conducting field research in a different cultural context.

A major issue that stirred my mind was the financial budget constraints. Although my personal relations in Hong Kong allowed me to live at very moderate cost, I still expected to have very high expenses. I therefore applied for funds in Austria, which were all rejected due to a diffuse and highly questionable research approach and a perceived lack of relevance for the Austrian economy. With hindsight I must stress that at the time of application my research project was not enough focused and yet, I chose to go ahead.

Previous work experience had taught me that I could only put a foot into Hong Kong-based multinational companies if I was able to show up with a recommending voice. Therefore, some Austria-related institutions were contacted, with the intention of finding adequate intermediaries. In order to cope with expected and unexpected fallacies during the empirical part of my research, I contacted one of the local universities in the hope of finding local researchers.

After six months of preparation I felt confident enough to move the work area to Asia. However, like any visitor doing research in a different cultural field, I encountered unexpected difficulties. The empirical phase took more than nine months - six months more than initially calculated. There were several reasons for this delay. Firstly, the Asian economic crisis fully hit Hong Kong during the years 1998 and 1999. Hence, the economic pressure caused major organizational restructuring. The increasing trend of shifting the process of strategic decision making into a geographically more secure location added to the difficulties in finding appropriate research sponsors. Furthermore, the issue of confidentiality, localisation of staff, and culture-based resistance toward the research project led to firms refusing to participate in the research project. 
Finally - after almost three months of company recruiting - I found three companies that were willing to co-operate in my research project.

To conclude, the research process required a lot of flexibility to keep up with the fluctuating requirements regarding research logistics and changes in the research methodology. The research process consumed a lot of my energy and financial budget, and it took all my courage not to give up in the middle of the research. However, the positive aspects of the trade-off were stronger and finally kept me on task. I made many acquaintances among the Chinese and people of other cultures, and the research team received very positive feedback. In the end, I believe that this project made a contribution - however small - to the attempt to narrow the gap between research and practice.

Another major period during this stage of doctoral research was finishing up the theoretical part. I clearly remember the statement of my second supervisor who aptly said, "Now, you know what this phase is all about - it is like 'living a monk's life - but you'll soon get over it'. Hours of intensive reading and typing alternated with hours in search of distraction, including cleaning my apartment, eating unhealthy food, watching television, and many more things. Once a section was finished, I felt like celebrating the moment with a big party and I completely fell in love with what I wrote. This was a habit that I trained toward perfection, but it turned out to be very hurtful once it came to the revision part. Weeks of painful re-working and re-writing occupied my mind at all times - in the evenings, at night, and during the weekends.

What proved to be helpful during this time was that I intensified my writing of papers for conferences and diverse journals. To a certain extent, this practice provided me with the contact toward the outside world and assured me of the value of my work once a paper was accepted and published. As time allowed, I also got involved in some consultant projects in completely different areas. This change helped to clear my mind and guaranteed an efficient use of my time, which otherwise would have been filled with too much sleep and other non-motivating activities. 


\section{Personal Experience: Joëlle Vanhamme}

The first hardest part of my $\mathrm{PhD}$. has been me spending hours in the psychology library trying to understand what was, sometimes, double-Dutch for me. It was also hard to build a bridge between the literature and the marketing and managerial issues. Moreover, I could not find many people within the department to discuss my research with, as my marketing colleagues were only vaguely familiar with psychology. This was the reason why I decided to embark on an MA in Psychology, a decision that helped me in several ways. First, it gave me the necessary background to psychology for carrying out my research. Second, it offered me the opportunity to get to know and to discuss with knowledgeable professors in psychology in addition to candidates in psychology. Third, these professors gave me important references and valuable comments, and also put me in contact with researchers working specifically on the emotion of surprise. Thanks to them, I received working papers and unpublished papers that helped me tremendously in my literature review. All in all, I no longer felt like being on a "shaky boat".

I also participated in conferences and doctoral seminars. I really enjoyed my first conference: I was quite surprised because everyone was friendly and encouraged me to continue my research. Presenting my research also helped me because I received valuable comments. With people coming to me for discussing the topic or for congratulating me, I had for the first time the impression that my research subject was interesting - also for other researchers.

I started networking with other candidates in marketing during my first doctoral seminar, and I also started to write articles with some of these candidates. One such candidate was Adam Lindgreen who introduced me to the University of Auckland, which invited me to be a visiting research fellow for six months. The stay was economically possible thanks to a grant of about US\$ 3,500 from the Belgian State to cover travelling and accommodation expenses. This first research experience abroad was my beginning of travelling around the globe. Later, a member of my doctoral committee offered me the opportunity to apply for a two-month full-paid junior research fellowship with his university. This really helped a lot when I carried out some of my field studies. 
With no additional budget for research, finding money for going to seminars and conferences and for carrying out my research has been a real problem for me, which has caused much stress throughout the whole $\mathrm{PhD}$. process. Since any grant only covers the travelling I have had to pay all accommodation costs and conference fees myself. Moreover, I have experienced financial problems when I wanted to carry out my field studies and have been dependent upon the generosity of companies and other universities that have invited me. For me, struggling for money has really been a nightmare and a huge waste of time.

I have appreciated that the doctoral programme at my university is very formalised. You will need to submit a proposal, which you will defend. The jury consists of the so-called Doctoral Commission (the same for all candidates within the department) and Supporting Committee (i.e., your supervisor(s) and two other academics you may think can guide you). I chose the members in such a way that they would have the complementary fields of expertise needed for my research (e.g., psychology, statistics, etc.). Then you embark on course programme (e.g., research methodologies). A year after the proposal, you are encouraged to hand in the literature review and the research methodology chapters after which it is decided whether or not you are able to go on with the research. From then on, you will meet once a year with the Supporting Committee and discuss your research. When you have actually finished your research, you meet with the Doctoral Commission, the Supporting Committee and two external examiners - first for the private defence and, subsequently, the public defence). At each stage, I received comments upon my work and integrated these comments into my thesis. This brought about the following advantage: I wrote my thesis at the same rate as I progressed, which meant that I should be avoided negative surprise during my private defence. In parallel to writing my thesis, I also wrote articles for journals and conferences.

\section{The Authors' Best Pieces of Advice}

How to carry out research in a different cultural environment? Researching in different cultural settings requires a high degree of flexibility in terms of financial budget, time and research methods to apply. Therefore, it is recommended to plan ahead very well (e.g. apply for funding; 
reading literature regarding the specific culture; learn the language of the country if necessary; get information on local infrastructure) and always include a buffer for prolonging your stay in the foreign country if necessary. Be prepared to use an alternative research methods, which still fit into your original research approach. Network with the universities (and other institutions or people) located at your chosen place so that you have direct access for help if problems occur.

Where and how do you network? An easy way of networking is to meet and discuss with your supervisors. You might want to consider becoming involved in your department's activities, such as teaching and coaching, so as to get a healthier balance of activities. But you should also try to see colleagues and candidates at other universities and at conferences. It might be beneficial to visit 'affiliated' departments, such as sociology, psychology, economics, etc.

Why do you publish? One reason for publishing is that the papers and articles will help you in the write-up of the doctoral thesis, as you have already finished considerable sections of the thesis. On top of that, you will have received valuable feedback from colleagues and you have also built on your curriculum vitae. You should strive for higher-rated journals. It is also advisable to submit pieces on managerial implications for magazines that are intended for practitioners.

How do you keep efficient time management? You are capable of completing a doctoral programme if you have first been accepted into one. If, however, you do not complete the programme the reason is probably that you have not kept efficient time management. Be strict about your work schedule: for example, if you work eight hours a day every single day of the week you will actually have put in a lot of work at the end of day. You do need breaks, however, so reward yourself once in a while. You take time off but you come back with more energy. 
Table 2. Issues to be considered under the second phase

\begin{tabular}{|c|c|}
\hline Issue & Examples \\
\hline $\begin{array}{l}\text { How to carry out research in a different cultural } \\
\text { environment? }\end{array}$ & $\begin{array}{l}\text { - Grant application for research budget } \\
\text { - Preparation with regards to language, culture, } \\
\text { infrastructure } \\
\text { - Networking with universities and other } \\
\text { institutions/private persons located in the specific } \\
\text { country } \\
\text { - Setting up a research plan with detailed description } \\
\text { of methods to be applied + possible alternatives }\end{array}$ \\
\hline Where and how do you network? & $\begin{array}{l}\text { - } \quad \text { The department and the university } \\
\text { - } \quad \text { Doctoral colloquiums, seminars and conferences } \\
\text { - Supervisors, colleagues, researchers and candidates } \\
\text { - } \quad \text { The Internet (e.g., Elmar list, ACR list) }\end{array}$ \\
\hline Why do you publish? & $\begin{array}{ll}\text { - } & \text { Valuable feedback } \\
\text { - } & \text { Form parts of the thesis } \\
\text { - } & \text { Building your curriculum vitae } \\
\text { - } & \text { Conferences and journals } \\
\text { - } & \text { Practitioners' magazines }\end{array}$ \\
\hline How do you keep efficient time management? & $\begin{array}{l}\text { - Tight schedule } \\
\text { - Rewards for sticking to the schedule }\end{array}$ \\
\hline
\end{tabular}

\section{Phase Three: Reaching Closure}

\section{Personal Experience: Adam Lindgreen}

I have always felt that when you have carried out your research according to well-established scientific methodologies passing the course or finishing the paper or thesis was mostly a matter of presenting the work in a readable and enjoyable manner. The thesis is a good story. This means in particular - that the candidate should give careful attention to the layout of the thesis and using a consistent vocabulary and grammar. Although I spent hours on polishing my sentences I would still have a qualified person to proof read my thesis.

In the case of qualitative research, tables, extended matrices and graphs may facilitate the presentation of the research data and the conclusions. Otherwise, going through the thesis could be a task too tremendous. For example, I relied heavily on quotations when I drew my conclusions I used two tables: The first table would list the research questions and the research 
findings (individually numbered). The second table would again list the research questions, but also the case evidence, which by way of the numbers would link back to the research findings. This meant that I needed only to use a limited number of quotations in my discussion of a particular case.

And so arrived the day when I sent off my doctoral thesis (22 May 2000). The day after, I left for a conference in the Netherlands and when I arrived home to New Zealand I finished up some administrative work over the next two weeks. Then I rewarded myself with a week's vacation (Tahiti and the Easter Island) before I presented at a conference in Buenos Aires and at another one in Derby. I had been in regular contact with my supervisor since I had sent off my thesis and he had told me that I had done a good job. So the day before the actual defence, I relaxed and went to watch "The Gladiator". Next day (7 July 2000), I left early and arrived to Cranfield University in the morning. I had an office for myself and spent three hours looking through the thesis. I then had my defence, which was a very pleasant experience with the examiners being genuinely interested in the subject. And that was that.

\section{Personal Experience: Christine Vallaster}

Most of the times this stage was characterised by great motivation and self-discipline. During the last weeks I spent a huge amount of hours in re-writing, re-editing, and re-arranging texts, figures, and tables. Although there are a lot of guidelines on how to finally present your doctoral research there is only one recommendation: be consistent in your arrangement and choose one that looks good in style and structure. As I did not write my doctoral research in my mother tongue I had someone to correct my English.

As I finally could see light at the end of what had been a very long tunnel I was highly motivated and pushed myself toward endless concentration and efficient working. In fact, I developed an immense drive to finish up my doctoral research. 
The requirement for defending your dissertation is different from country to country. In Austria, for instance, doctoral research students need to choose three professors (one of whom is your first supervisor) from different subjects. Depending on the area, you will get some extra literature to read through and in form of a discussion you will be evaluated. At this time I was completely exhausted and I therefore prepared myself marginally by flicking through the literature I was recommended to read. In fact, I really enjoyed my defense because I finally met people who showed - apart from my supervisor - genuine interest in what I had to say on this particular subject.

To conclude, in an attempt to depict the phases I went through whilst being a doctoral research candidate I created the following illustration (see Figure 2).

The zick-zack curve was caused mainly be two major issues:

1) Often I ignored my supervisor's hint to be more patient, especially at the beginning of my research. Many times, my acting was ahead of my state of thinking and this eventually caused insecurity and frustration.

2) Imbalances in my 'emotional household' were caused by the ending of a relationship - a situation that can happen to everybody. However, the process of reading and writing is a rather lonesome work where a high degree of concentration is required. Hence, you might imagine the influence your private life can have on the progress of the research project.

Overall, I was very lucky that I was able to share moments of complete desperation and happiness with people who supported me throughout this process. I was striving for excellence and did not always choose the easiest way of doing things. Going through an enormous learning process "ripened" my personality, giving me the satisfaction that I could not have done better under the given circumstances. 
Figure 2. Highs and lows during my doctoral programme

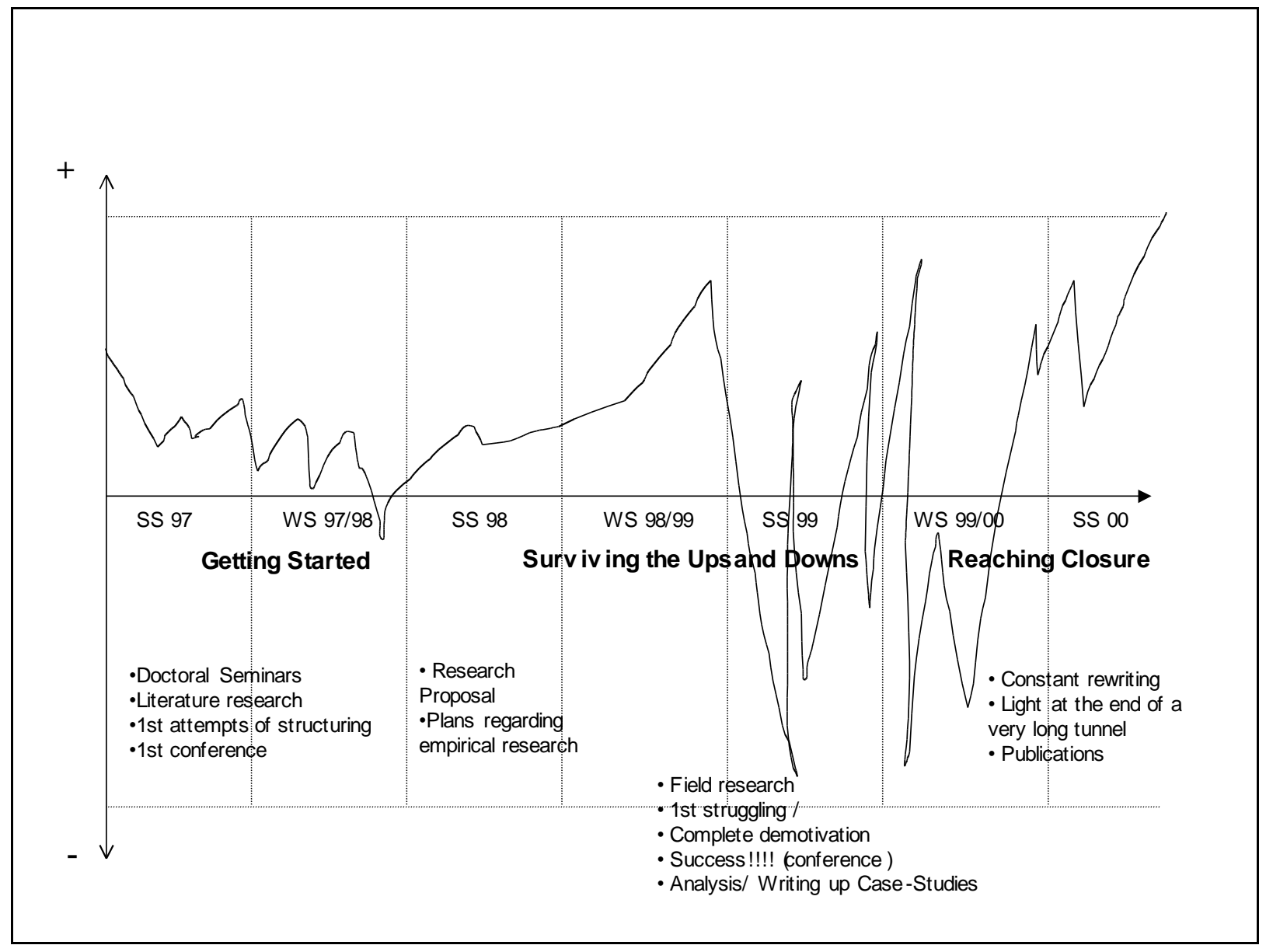

\section{Personal Experience: Joëlle Vanhamme}

I have not yet finished my programme, but as I have already written up and defended much of the thesis I still have some experiences to share. One major mistake that I originally did was to pay no attention to the official guidelines for the layout of any thesis. Since theses are to be published in the university collection there are certain rules, for example the size of the margins. As a result, I had to change the layout after having written some 200 pages, which was a huge waste of time: all the tables and figures had to be redesigned!

It might also be usefull to pay attention to possible deadlines for handing in your thesis and whether some funding is available for publishing your thesis (publishing your thesis might be 
expensive). This is something that you should know way before finishing your thesis because at that time you will have a lot of other things to be busy with.

Up to now I have always been very nervous before any defense but have, in fact, noticed that it goes well. I guess that as long as you do your job properly there should be no real problem and, furthermore, it is better not to worry too much beforehand because it can work against you. I have always paid full attention to the comments that my Supporting Committee has made (during the defences) and incorporated these comments into my thesis. This means that for the final defence the only thing I will need to do is to write up the latest results and the discussion and conclusion chapters. This alleviates much of the stress at the very end of the programme.

Boileau, a French author, once said, "What is clearly thought is clearly explained, and the words for saying it come easily". That is, you strive to structure your thesis, to write using proper grammar and to explain clearly. I have personally made use of many graphical diagrammes and tables to facilitate the reading process.

\section{The Authors' Best Pieces of Advice}

How do you write up the doctoral thesis? You should be aware whether or not there are any official guidelines for the format of the thesis. The examiners are not familiar with the topic of your research so you must present your findings in a structured and consistent manner. Make the reading a pleasant experience. Consider using graphical diagrammes and tables.

How do you prepare for the defence? There are a number of questions that the examiners are likely to ask you. They may want you to reflect on the most significant research findings. For example, how do the findings fit into the wider landscape? What are their managerial implications? The examiners may also want you to reflect on what could have been done differently. Could the topic, focus, sample and/or research methodology have been improved in some way? Overall, the examiners will want you to demonstrate that you can test your own and other people's ideas, and that you have made an original contribution to the scientific pool of 
knowledge. That is, are your research findings publishable? At the defence, you should know when to defend your ideas resolutely and when to "back off". Saying something along the lines "Now there is an interesting thought. I did not think of that, but can definitely see how doing so could have been useful" will not harm you, but please the examiners.

\section{Table 3. Issues to be considered under the third phase}

\begin{tabular}{|c|c|}
\hline Issue & Examples \\
\hline How do you write up the doctoral thesis? & $\begin{array}{l}\text { - Use tables, extended matrices and graphs when } \\
\text { presenting research data and drawing conclusions } \\
\text { - Make the thesis readable and enjoyable }\end{array}$ \\
\hline How do you prepare for the defence? & $\begin{array}{l}\text { - Do not stress for the defence - you are all but done } \\
\text { - What are the most significant research findings? } \\
\text { - Could the doctoral research have been improved? } \\
\text { - Have you made an original contribution to the } \\
\text { scientific pool of knowledge? } \\
\text { - Know when to defend your ideas resolutely and } \\
\text { when to 'back off' }\end{array}$ \\
\hline
\end{tabular}

\section{Overall Conclusions}

We have shared with the reader our personal experiences of going through a doctoral research programme. Based on our individual experiences, we have tried to identify the most important Dos and Don'ts, which hopefully can give you an indication of what to expect from a doctoral programme. They are also intended to guideline candidates.

\section{The Dos}

- Consider the constraints of your financial budget.

- Strive for achieving an excellent doctoral thesis, but not necessarily a perfect one.

- Start the doctoral research early - and finish it early, too.

- Network within the department and university, and at international seminars and conferences.

- Publish the research findings, but not at the expense of your thesis.

- Set goals, because time management is vital for focused and efficient work. 
- Take courses in a field if you feel that you are lacking some theoretical background.

- Participate in doctoral colloquiums, seminars and conferences.

- Spend time with a foreign university, which, perhaps, has a strong reputation in your field.

- Try to build up your own brand name.

- Be patient - and yet persistent - with yourself and your social environment.

\section{The don'ts}

- Do not accept the 'This is the way we do things around here' attitude. Fight for your ideas.

- Do not be constrained by budget - be prepared to seek funding from many sources.

- Do not start your data collection before you are prepared in terms of a conceptual framework.

- Do not wait until the last moment for writing up your thesis, but do it progressively.

- Do not stay alone, but share your views with other candidates and researchers.

- Do not consider your doctoral thesis more than the first step in your research career.

How should an article that shares such very personal experiences be finished? The article has focused on the experiences of doctoral candidates so perhaps the following story (which we became aware of through the Internet) would be appropriate. It tells what makes the ideal supervisor - and the secret of your success:

A bunny rabbit is sitting in a clearing in the woods, typing away on his laptop computer. A fox comes along and asks the bunny rabbit what he is doing. The rabbit replies, "I'm writing my PhD dissertation." "What are you writing about?" asks the fox. "The title of the thesis is 'Predation by Bunny Rabbits on Foxes and Wolves'," says the rabbit. "Predation by rabbits on foxes and wolves?" exclaims the fox, "But rabbits don't prey on foxes and wolves -- that's counterintuitive!" "Well" says the rabbit "perhaps you would like to come down into my burrow and see my data!" The fox follows the rabbit down the rabbit hole, and a few minutes later the rabbit emerges brushing fox fur from his arm and picking bits of fox out of his teeth. He returns to his typing.

A few minutes later, a wolf comes by, and asks the rabbit what he is doing. "I'm writing my PhD dissertation; it's titled: 'Predation by Bunny Rabbits on Foxes and Wolves'," says the rabbit. "Predation by rabbits on foxes and wolves?" exclaims the wolf, "But rabbits don't prey on foxes and wolves -- that's 
counterintuitive!" "Well," says the rabbit, "Perhaps you would like to come down into my burrow and see my data!" The wolf follows the rabbit down the rabbit hole, and a few minutes later the rabbit emerges brushing wolf fur from his arm and picking bits of wolf out of his teeth. He returns to his typing.

A few minutes later, a grizzly bear emerges from the rabbit hole, turns to the bunny rabbit, and says, "The second chapter looks fine. I'll read the third chapter next week."

And so, the moral of the story is that it does not matter if your research is counterintuitive, as long as you have the right supervisor.

\section{Bibliographical Notes}

Adam Lindgreen: After graduating in Chemistry, Engineering and Physics, Adam Lindgreen finished an MSc in Food Science/Food Technology at the Technical University of Denmark; an MBA at the University of Leicester in England; and a One Year Postgraduate Programme at the Hebrew University of Jerusalem in Israel after which he worked as a consultant for Andersen Consulting in Denmark/Norway. He then completed a PhD in Marketing at Cranfield University in England - with 18 months as a Visiting Research Fellow at the University of Auckland in New Zealand. He is now with Catholic University of Louvain in Belgium and represents its Department of Marketing in the Community of European Management Schools' inter-faculty group 'Marketing'. Adam has received three Best Paper awards (including Best Doctoral Paper at the Academy of Marketing: Doctoral Colloquium in 1999) at international marketing conferences.

Contact address: Adam Lindgreen, Unité Marketing, Institut d'Administration et Gestion, Université catholique de Louvain, 1 Place des Doyens, 1348 Louvain-la-Neuve, Belgium. Email Lindgreen@mark.ucl.ac.be. Telephone + 32 -10478481. Fax +32 - 10478324.

Christine Vallaster: Christine Vallaster received her Ph.D. from Leopold-Franzens University of Innsbruck: Department of Value Process Management/Marketing Group where she has been working as a researcher and lecturer. Additionally, she works as a consultant on a project-base in both national and international fields. The topic for her doctoral research was "Strategy-making by Multicultural Workgroups" with the empirical research carried out in Hong Kong (China). She has been awarded the Best Doctoral Paper by the Australia-New Zealand Marketing Academy in 
1998 and received a doctoral dissertation award provided by the Academy of Marketing Science (AMS) in 2001 (San Diego, USA).

Contact address: Christine Vallaster, Department of Value Process Management/Marketing Group, Leopold-Franzens University of Innsbruck, Universitätsstrasse 15, 6020 Innsbruck, Austria. Email Christine.Vallaster@.uibk.ac.at. Telephone + $43-512507$ 7219. Fax + $43-5125072842$.

Joëlle Vanhamme: Joëlle Vanhamme is a doctoral candidate with the Catholic University of Louvain. After graduating in Management, she obtained an MA in Management at the Catholic University of Louvain; a CEMS MA from the Community of European Management Schools; and an MA in Psychology from the Catholic University of Louvain. Joëlle has worked as a researcher, lecturer and consultant in Belgium, Germany and the Netherlands. The topic for her doctoral research is the emotion of surprise. She was awarded the prestigious Belgian National Fund for Scientific Research Fellowship grant to undertake her doctoral programme, and she has been awarded two Best Paper awards (including Best Doctoral Paper at the Academy of Marketing: Doctoral Colloquium in 2000) and two runner-ups at international marketing conferences.

Contact address: Joëlle Vanhamme, Unité Marketing, Institut d'Administration et Gestion, Université catholique de Louvain, 1 Place des Doyens, 1348 Louvain-la-Neuve, Belgium. Email Vanhamme@ mark.ucl.ac.be. Telephone + 32 -10478478. Fax $+32-10478324$.

\section{References}

Baker, M. J. (2000a), "Writing a research proposal", The Marketing Review, Vol. 1, No. 1, pp. 61-75.

Baker, M. J. (2000a), "Writing a literature review”, The Marketing Review, Vol. 1, No. 2, pp. 219-247.

Clark, N. (1986), "Writing-up the doctoral thesis", Graduate Management Research, Autumn, pp. 25-31.

Drummond, W. J. (1995), Writing Your Thesis, Nagare Press, Palmerson North.

Lewins, F. W. (1993), Writing a Thesis: A Guide to its Nature and Organisation, 4th ed., Bibliotech: Anutech, Canberra.

Mace, G. (1997), Guide d'Elaboration d'un Project de Recherche, 2nd ed., De Boeck, Brussels. Madsen, D. (1983), Successful dissertations and Theses, Jossey-Bass, San Francisco, California.

Mauch, J. E. (1998), Guide to the Successful Thesis and Dissertation: A Handbook for Students and Faculty, 4th ed., M. Dekker, New York. 
Perry, C. (1999), "A structured approach for presenting theses", Australasian Marketing Journal, Vol. 6, No. 1, pp. 63-85.

Pratt, J. M. (1984), "Writing your thesis", Chemistry in Britain, December, pp. 1114-1115.

Tremewan, T. (1997), Write, Edit, Print: Style Manual for Aotearoa New Zealand, AGPS Press and Lincoln University Press, Canberra.

Turabian, K. L. (1996), A Manual for Writers of Term Papers, Theses and Dissertations, 6th ed., University of Chicago Press, Chicago, Illinois.

Witcher, B. (1990), "What should a Ph.D. look like? Graduate Management Research, Vol. 5, No. 1, pp. 29-36.

Weggel, O. (1994), China, C.H. Verlag, München 